\title{
Gender, self-confidence, sports, and preferences for competition
}

Irene Comeig, University of Valencia \& ERICES

Alfredo Grau-Grau, University of Valencia

Ainhoa Jaramillo-Gutiérrez, University Jaume I \& LEE, Castellón

Federico Ramírez, University of Valencia

July 2015

The authors thank Pedro Carmona and Alexandre Momparler, University of Valencia for their careful reading and suggestions. Irene Comeig and Ainhoa Jaramillo-Gutiérrez acknowledge financial support from Spanish Ministry of Economy ECO2013-46550-R grant. Send correspondence to Irene Comeig, Department of Corporate Finance and ERICES, University of Valencia, Avda. Tarongers, s/n., 46022 Valencia, Spain (irene.comeig@uv.es); Alfredo Grau-Grau, Department of Corporate Finance, University of Valencia, Avda. Tarongers, s/n., 46022 Valencia, Spain (alfredo.grau@uv.es); Ainhoa Jaramillo-Gutiérrez, Economics Department, University Jaume I, Castellón, Spain (jaramill@uji.es); Federico Ramírez, Department of Corporate Finance, University of Valencia, Avda. Tarongers, s/n., 46022 Valencia, Spain (federico.ramirez@uv.es). 


\begin{abstract}
Gender differences in the willingness to compete may explain the small percentage of women in top-level positions in business, science, or politics. This research examines with a fuzzy-set qualitative comparative analysis (fsQCA) the conditions, including gender, that relate to competition preferences and the different paths that may lead to decide enter competition. The results of the economic experiment show that no single condition but combinations of characteristics explain preferences for competition. Furthermore, results show that experience in competitive sports relates to a higher self-confidence and increases the willingness to enter in competitive systems. Interestingly, one of the causal paths leading to enter competition is being a risk-averse woman with experience in competitive sports. These results provide insights to guide policy interventions to reduce the gender gap in preferences for competition and, therefore, to rise the percentage of women in top-level positions.
\end{abstract}

Keywords: Behavior; competition; experimental economics; fsQCA; gender differences; risk aversion; self-confidence 


\section{Introduction}

Recent research in economics shows a gender gap in the willingness to compete, with women shying away from competition more than men do (Croson \& Gneezy, 2009; Niederle \& Vesterlund, 2007; 2011). This gender difference in preferences toward competition seems critical to explain the small percentage of women in top-level positions in business, science, or politics (Blau et al., 2010; Cason et al., 2010; Datta Gupta et al., 2013; Dohmen \& Falk, 2011; Gneezy et al., 2009; Gneezy et al., 2003; Gneezy \& Rustichini, 2004; Niederle \&Vesterlund, 2007; 2011; Weichselbaumer \& Winter-Ebmer, 2007). Consequently, research and policy interventions explore ways to increase women's competitive behavior (Balafoutas \& Sutter, 2012; Calsamiglia et al., 2013; Miller \& Segal, 2012; Niederle et al., 2013; Villeval, 2012).

However, competitive behavior might not always be desirable. Some studies relate women's lower preferences for competition to positive consequences for the general economic well-being. Eckel and Fullbrunn (2015) show that increasing the fraction of women traders in the market reduces the magnitude of the speculative price bubbles such as the one causing the financial crisis in 2008. They argue that women's higher risk aversion and lower preferences for competition seem to trigger this result. Charness and Rustichini (2011) relate women's lower willingness to compete with higher cooperative behavior. Furthermore, their research on gender differences in cooperation suggests that females cooperate more often and men cooperate less often when their gender peers observe them. Charness and Rustichini (2011) conclude that men prefer signaling to other men that they are tough, whereas women prefer to show other women they are cooperative. This result appears to indicate that salient group membership such as gender influences behavior. Similarly, Ackerlof and Kranton (2010) and Cohn et al. (2014) show how identities, and not just economic incentives, shape economic decisions. 
Differences in willingness to compete may relate to not only gender differences in social identity or personal traits such as cooperativeness and risk aversion but also to differences in confidence. Kamas and Preston (2012) find that, conditional on ability, self-confidence eliminates gender differences in decisions to enter winner-take-all (WTA) competition. However, this result does not hold for business school students in the Kamas and Preston (2012)'s analysis. Gender differences in willingness to compete persist in business school students even after accounting for risk aversion and confidence. Conversely, women outcompete men in Gneezy et al.'s (2009) study in a matrilineal society. These findings, together with previous literature's results depending on the tasks performed, may indicate that selfconfidence plays a role in the willingness to compete. The inclusion of self-confidence in studies on gender differences in competition preferences is important for policy interventions because appropriate education and information may correct lower confidence.

Policy interventions devoted to increase women's willingness to compete need to take into account the related conditions and behaviors. Consequently, research methods should account for the causal complexity and should study the different paths that could lead to decide entering competition.

Previous studies mainly present laboratory economic experiments and apply econometric models to analyze the main net effects of gender on the willingness to compete. This study aims to analyze the recipes of conditions that relate to competition preferences, including gender, and the different paths that lead to decide entering competitive environments. Thus, this study presents a laboratory economic experiment on preferences for competition, and uses a fuzzy-set qualitative comparative analysis (FsQCA) to analyze results. The fsQCA (Ragin, 2000) helps capture complex patterns of causation and shows different combination of conditions that could lead to the outcome. 
The results show that differences in preferences for competition do not come from the gender alone, but from several combinations of causal conditions. Furthermore, results suggest that experience in competitive sports relates to a higher self-confidence and serves as a path to increase integration in competitive systems.

Following this introduction, section 2 presents the details of the experimental design. Section 3 presents the method of analysis and reports the results. Section 4 discusses the results and offers some conclusions.

\section{Experimental design and procedures}

To explore the conditions related to the decision of entering competition, and the gender effect, this study replicates Niederle and Vesterlund's (2007) economic experiment with undergraduate students from economics and business careers. This study experimentally tests subjects' self-confidence and cooperative behavior, measures attitudes toward risk, and records subjects' experience in competitive games and sports. The study further analyzes the results using fsQCA.

The laboratory economic experiment starts, as in Niederle and Vesterlund (2007), with subjects adding sets of five two-digit numbers during five minutes at a piece-rate payment scheme of 0,25 euros per correct addition (Round 1 in Task 1). In a second round, subjects repeat the task under a WTA competitive payment scheme: A tournament in groups of four randomly selected subjects (two men and two women) in which only the subject who solves the largest number of correct additions within the group receives a payment (1 euro per correct sum). Subjects in the third round of Task 1 repeat the task and decide which one of these two payment schemes they prefer to apply. Differently from Niederle and Vesterlund (2007), subjects do not receive information about the number of their correct additions until the end of the rounds. Before receiving the information, subjects have to answer an incentivized question 
on their relative performance (within the group of four). The subject's believes on their relative performance compared to their actual position within the group measure each subject's selfconfidence.

After this task, subjects start a decomposed game to test their cooperative behavior (Brosig, 2002; Liebrand, 1984; McClintock \& Liebrand, 1988). Subjects make 24 choices between two "own-other" payoff combinations. Payoffs come from all 24 choices subjects and partners make. Using a standard classification procedure for this technique, subjects classify for this study as cooperative or non-cooperative (Griesinger \& Livingston, 1973).

The third task measures attitudes toward risk. Subjects make choices in nine lottery pairs as in Comeig et al. (2013). The lotteries' design follows Blavatskyy's (2009) test on risk attitudes, which builds on Holt and Laury (2002).

At the end of the experiment, subjects answer a social questionnaire that includes questions about experience in competitive videogames and sports; subjects receive the payoffs in cash (19 euros on average) afterwards.

Table 1 describes the conditions this research examines and the data from the experiment.

Table 1 here

The 104 subjects of the experiment are students from the Economics, Business, Finance and Accounting, and International Business degrees at the University of Valencia (52 men, 52 women). The computerized experiment was run in the fall 2014 at the Laboratory for Research in Experimental Economics (LINEEX). At the beginning of the experiment, the subjects read the instructions and solved their questions. During the experiment, subjects received no feedback on their performance and could not communicate with other subjects. (Instructions are available upon request). 
The fsQCA analysis of the experimental data includes only 68 subjects (31 men and 37 women); that is, subjects who were consistent in the risk-attitude elicitation task. Consistent subjects are those with a unique switching point (USP) from the safe option to the risky option. Risk-averse subjects switch to the risky option after the fifth lottery (I $>5)$. Additionally, fsQCA requires the calibration of the condition that proxies individual's ability, the number of correct additions in the piece rate round (SCOR1). The number of correct sums in round 1 of Task 1 (with the minimum at 0 sums, the maximum at 13 and average at 5.57 correct sums) translates into a five-point scale $(0 ; 0.2 ; 0.5 ; 0.8 ; 1)$ and three percentiles $(0.95 ; 0.5$; and 0.05$)$ of the condition's presence (Ragin et al., 2009).

This study uses fsQCA to analyze the experimental results because this type of analysis shows the different paths that lead to reach the outcome, not only the main influences, which is especially appropriate to analyze behavior, connections among experiences and behavior, and to inform policy-makers (Woodside, 2013; 2014).

\section{Results}

Figure 1 and Figure 2 show a descriptive overview of the experimental results of Task 1 by round and gender. Results from round 3 show that women tend to enter competition less than men do (see Figure 2, graph B). However, whereas Niederle and Vesterlund (2007) find $73 \%$ of men and $35 \%$ of women choose competition, the gender difference is smaller in this study: $55 \%$ of men and $45 \%$ of women decide to enter competition. Kamas and Preston (2012) show no significant difference between men and women for STEM majors' students but do show a significant difference for business school students because of the highly competitive behavior of men studying business. 
In addition, in line with previous literature, results show that the number of correct additions is higher for subjects in WTA tournament than in the piece-rate payment scheme (see Figure 1, rounds 1 and 2, and Figure 2, graph A).

Results in this experiment replicate previous findings. However, instead of explaining these findings with a standard analysis on gender main effects, this study applies the fsQCA (fsQCA 2.0, www.fsqca.com, from Ragin et al., 2009) to examine the combinations of causal conditions that explain preferences for competition, including the effect of gender on those preferences.

Figure 1 here.

Figure 2 here.

The fuzzy-set qualitative comparative analysis (fsQCA) models the concept of conjectural causation: combinations of various causal conditions, rather than one condition alone, may lead to the outcome.

\subsection{Necessary conditions}

The results of the fsQCA in Table 2 show than none of the causal conditions alone, including gender, are a necessary condition for the outcome. A condition or a combination of conditions is necessary or almost always necessary if the consistency score exceeds 0.9 (see Schneider et al. 2010, p. 254 for further explanation on the measure, or Ragin, 2006).

The gender (GEN, gen) of the subjects is the less necessary condition (consistency score $=0.5)$ for the decision to enter the WTA tournament $(\mathrm{dec})$. However, the lack of mathematical ability (scor1), and having previous experience in competitive sports (SPOR) are the conditions almost necessary to decide whether to enter the WTA competition (dec), with consistency scores of 0.87 and 0.82 , respectively. 
This result confirms that differences in preferences for competition do not come from the individual's gender alone, but from sets of connected conditions.

Table 2 here.

The last part of Table 2 shows whether two conditions, one or the other, are necessary conditions for the outcome, that is, if these two conditions are "substitutable necessary conditions" in fsQCA (Ragin, 2006). Having previous experience in competitive sports relates to high self-confidence (consistency score of OVERCONF+SPOR $=0.94$ ), and one or the other are necessary conditions for the outcome. However, having previous experience in competitive sports acts as a functional equivalent to masculine gender (consistency score of GEN+SPOR = 1), that is, men (GEN) have more experience in competitive sports than women have.

Furthermore, these two expressions are not trivial for the decision on entering or not WTA competition (coverage rate of OVERCONF+SPOR and GEN+SPOR are 0.52 and 0.51 , respectively). A necessary condition is trivial and yields a coverage rate near 0 if the condition occurs in all cases regardless of the presence or absence of the outcome (Ragin, 2006).

This result suggests that the active promotion of competitive sports among women may be a recommendable policy intervention to increase women's self-confidence and women's integration in competitive systems as businesses, science, or politics, in line with cooperation practitioners' wisdom (Meier, 2005; Kirk, 2012). However, fsQCA results do not explain whether the strong relationship between men and competitive sports comes from inherent gender preferences, social identity, or education. The question on the self-selection in competitive sports remains open.

\subsection{Sufficient conditions}


Table 3 presents the intermediate solution with the conditions and/or combination of conditions sufficient to reach the outcome. Ragin (2008) recommends the intermediate solution for interpretation of results.

Table 3 here.

Each line describes a combination of conditions (or causal path) that leads to the decision of entering the WTA tournament instead of selecting a piece-rate payment. As Table 3 shows, all causal paths consist of combinations of conditions. No single condition is sufficient to account for entering the competition.

The total coverage of the seven causal paths in Model 1 is 0.62 , indicating that these combinations of conditions cover most of the subject's choices (dec).

The most important combination of conditions that leads to the decision of entering the WTA competition (raw coverage $=0.15$, unique coverage $=0.15$ ) is having experience in competitive sports and games, together with the lack of risk aversion and the lack of cooperative personality $\left(\mathrm{GAME}^{*} \mathrm{SPOR} *\right.$ averisk*coop). Previous literature results, which generally study main net effects in econometric models, traditionally capture this combination of conditions and thus relate gender differences in willingness to compete to women's higher risk aversion and social preferences towards cooperation and equality. However, analyzing results with fsQCA shows that this path is not the only path to decide entering a competition.

The second empirically important causal path that leads to the outcome (raw coverage $=0.15$, unique coverage $=0.12$ ) combines masculine gender with a risk-averse, cooperative, and not-overconfident attitude (GEN*AVERISK*overconf*COOP). This seems to indicate that men, even being risk averse, not-overconfident, and cooperative enter WTA tournaments.

The next three causal paths contain the experience in competitive sports (SPOR) among their conditions, which denotes the importance of experience in the decision to enter a WTA tournament. 
The third recipe contains experience in sports, overconfidence, and cooperativeness $($ game $*$ SPOR $*$ OVERCONF $*$ COOP $)($ raw coverage $=0.9$, unique coverage $=0.9)$.

The fourth recipe includes being woman among the conditions (gen*game*SPOR*AVERISK). Women with experience in competitive sports decide to enter competition even when being risk-averse (raw coverage $=0.9$, unique coverage $=0.9$ ). This result is important for policy interventions because women's experience in sports, contrary to personal traits (such as cooperativeness or risk aversion), might increase with appropriate information or the promotion of new and more women-appealing sports.

The second part of Table 3 presents the intermediate solution of Model 2, a model that excludes gender from the causal conditions. The total coverage of the causal paths in Model 2 is 0.56 (0.62 in Model 1), indicating that the gender effect is not decisive. Combinations of causal conditions other than gender cover most of the subject's decisions about entering competition (56\%).

The first and second combination of conditions leading to the decision of entering a WTA tournament instead of selecting a piece-rate payment (raw coverage $=0.27$ and 0.15 , unique coverage $=0.07$ and 0.06 , respectively) include experience in competitive sports (SPOR) in the recipe. The two next causal paths leading to the decision of entering a WTA tournament include OVERCONF among the conditions, which closely relates to experience in competitive sports (see necessary conditions). Thus, the intermediate solution of Model 2 again shows that experience in competitive sports relates to a higher self-confidence and increases the integration in competitive systems.

\section{Discussion and conclusions}

This study presents the first fuzzy-set qualitative comparative analysis (FsQCA) on gender differences in preferences for competition. Previous research analyzes the main effects of gender on the willingness to compete applying standard statistic and econometric models 
and generally finds that women present a lower preference for competitive environments. This study, however, seeks to analyze the connected conditions, including gender, that relate to competition preferences and the different paths that may lead to decide entering a competition. Understanding complex connections in behavior, preferences, and social experiences may help establish responsible policy interventions on the gender gap in the willingness to compete.

The fsQCA results on the economic experiment show that the willingness to compete does not come from the individual's gender alone but from sets of connected conditions. One combination of conditions that leads to enter competition is the lack of risk aversion and the lack of cooperative personality together with experience in competitive sports and games. This path reflects the main effects that generally show previous literature, which relate gender differences in willingness to compete to women's higher risk aversion, and preference towards cooperation and equality. However, analyzing results with fsQCA shows that this is not the only path to decide entering a competition.

Interestingly, one of the causal paths leading to enter competition includes being a woman among the conditions: Women with experience in competitive sports decide to enter competition even when being risk-averse. This result is important for policy interventions, because women's experience in sports might increase with proper information or by promoting sports attractive enough for women.

Furthermore, results show that experience in competitive sports relates to a higher selfconfidence and generates a higher willingness to enter in other competitive environments. These results provide interesting insights to guide policy interventions to reduce the gender gap in preferences for competition and, therefore, to rise the percentage of women in top-level positions and to reduce the gender gap in salaries. 


\section{References}

Ackerlof, G. A., \& Kranton, R. E. (2010) Identity Economics: How our Identities Shape our Work, Wages, and Well-Being. Princeton, NJ: Princeton University Press.

Balafoutas, L., \& Sutter, M. (2012). Affirmative action policies promote women and do not harm efficiency in the laboratory. Science, 335 (6068), 579-582.

Blau, F. D., Currie, J. M., Croson, R. T. A., \& Ginther, D. K. (2010). Can mentoring help female assistant professors? Interim results from a randomized trial. American Economic Review, 100(2), 348-352.

Blavatskyy, P. R. (2009). Betting on own knowledge: Experimental test of overconfidence. Journal of Risk and Uncertainty, 38(1), 39-49.

Brosig, J. (2002). Identifying cooperative behavior: Some experimental results in a prisoner's dilemma game. Journal of Economic Behavior \& Organization, 47(3), 275-290.

Cason, T. N., Masters, W. A., \& Sheremeta, R. M. (2010). Entry into winner-take-all and proportional-prize contests: an experimental study. Journal of Public Economics, 94(9$10,604-611$.

Calsamiglia, C., Franke, J., \& Rey-Biel, P. (2013). The incentive effects of affirmative action in a real-effort tournament. Journal of Public Economics, 98, 15-31.

Charness, G., \& Gneezy, U. (2007). Strong evidence for gender differences in investment. University of California at Santa Barbara WP. Available at SSRN 648735.

Cohn, A., Fehr, E., \& Maréchal, A. (2014). Business culture and dishonesty in the banking industry. Nature, 516, 86-89.

Comeig, I., Jaramillo-Gutiérrez, A. \& Ramírez, F. (2013). Do women self-select as good borrowers? WP-UJI 2013/14.

Croson, R., \& Gneezy, U. (2009). Gender differences in preferences. Journal of Economic Literature, 47(2), 448-74. 
Datta Gupta, N., Poulsen, A., \& Villeval, M. C. (2013). Gender matching and competitiveness: Experimental evidence. Economic Inquiry, 51(1), 816-835.

Dohmen, T., \& Falk, A. (2011). Performance pay and multidimensional sorting: Productivity, preferences, and gender. The American Economic Review, 101(2), 556-590.

Eckel, C. C., \& Füllbrunn, S. C. (2015). Thar SHE blows? Gender, competition, and bubbles in experimental asset markets. American Economic Review, 105(2), 906-920.

Gneezy, U., Leonard, K. L., \& List, J. A. (2009). Gender differences in competition: Evidence from a matrilineal and a patriarchal society. Econometrica, 77(5), 1637-1644.

Gneezy, U., Niederle, M., \& Rustichini, A. (2003). Performance in competitive environments: Gender differences. Quarterly Journal of Economics, 118 (3), 1049-1074.

Gneezy, U., \& Rustichini, A. (2004). Gender and competition at a young age. American Economic Review, 94(2), 377-381.

Griesinger, D. W., \& Livingston, J. W. (1973). Toward a model of interpersonal motivation in experimental games. Behavioral Science, 18(3), 173-188.

Holt, C. A. \& Laury, S. K. (2002). Risk aversion and incentive effects. American Economic Review, 92(5), 1644-1655.

Kamas, L. \& Preston, A. (2012). The importance of being confident; Gender, career choice, and willingness to compete. Journal of Economic Behavior and Organization, 83(1), $82-97$.

Kirk, D. (2012). Empowering girls and women through physical education and sport. Advocacy Brief UNESCO Bangkok. UNESCO Asia and Pacific Regional Bureau for Education, Bangkok, Thailand.

Liebrand, W. G. (1984). The effect of social motives, communication and group size on behavior in an N-person multi-stage mixed-motive game. European Journal of Social Psychology, 14(3), 239-264. 
McClintock, C. G., \& Liebrand, W. B. G. (1988). Role of interdependence structure, individual value orientation, and another's strategy in social decision making: A transformational analysis. Journal of Personality and Social Psychology, 55(3), 396-409.

Meier, M. (2005). Gender equity, sport and development. Working Paper, Swiss Academy for Development

Miller, A. R., \& Segal, C. (2012). Does temporary affirmative action produce persistent effects? A study of black and female employment in law enforcement. Review of Economics and Statistics, 94(4), 1107-1125.

Niederle, M., Segal, C., \& Vesterlund, L. (2013). How costly is diversity? Affirmative action in light of gender differences in competitiveness. Management Science, 59(1), 1-16.

Niederle, M., \& Vesterlund, L. (2007). Do women shy away from competition? Do men Compete too much? Quarterly Journal of Economics, 122 (3), 1067-1101.

Niederle, M., \& Vesterlund, L. (2011). Gender and competition. Annual Review of Economics, $3(1), 601-630$.

Ragin, C. C. (2000). Fuzzy-set social science. Chicago, IL: University of Chicago Press.

Ragin, C. C. (2006). Set relations in social research: Evaluating their consistency and coverage. Political Analysis, 14(3), 291-310.

Ragin, C. C. (2008). Redesigning social inquiry: Fuzzy sets and beyond. Chicago, IL: University of Chicago Press.

Ragin C. C., Drass, K, \& Davey, S (2009). fsQCA 2.0 [Computer Software]. Tucson, AZ: Department of Sociology, University of Arizona. Available at http://www.socsci.uci.edu/ cragin/fsQCA/

Schneider, M. R., Schulze-Bentrop, C., \& Paunescu, M. (2010). Mapping the institutional capital of high-tech firms: A fuzzy-set analysis of capitalist variety and export performance. Journal of International Business Studies, 41, 246-266. 
Villeval, M. C. (2012). Ready, steady, compete. Science, 335(3), 544-545.

Weichselbaumer, D., Winter-Ebmer, R., \& Zweimüller, M. (2007). Market orientation and gender wage gaps: An international study. Kyklos, 61(4), 615-635.

Woodside, A. G. (2013). Moving beyond multiple regression analysis to algorithms: Calling for adoption of a paradigm shift from symmetric to asymmetric thinking in data analysis and crafting theory. Journal of Business Research, 66(4), 463-472.

Woodside, A. G. (2014). Embrace $\square$ perform $\square$ model: Complexity theory, contrarian case analysis, and multiple realities. Journal of Business Research, 67(12), 2495-2503. 
Table 1. Outcome and causal conditions: Definition and estimate.

Condition

Definition

Value $=1$ for men

Value $=0$ for women

(GEN)

Decision in round 3 of

Task 1

(DEC)
Estimate

Mean

\begin{tabular}{|c|c|c|c|}
\hline $\begin{array}{l}\text { Gender } \\
(\mathrm{GEN})\end{array}$ & $\begin{array}{l}\text { Value }=1 \text { for men } \\
\text { Value }=0 \text { for women }\end{array}$ & Binary & 0.46 \\
\hline $\begin{array}{l}\text { Decision in round } 3 \text { of } \\
\text { Task } 1 \\
(\mathrm{DEC})\end{array}$ & $\begin{array}{l}\text { Value }=1 \text { for not entering } \\
\text { competition (chooses piece-rate } \\
\text { payment) } \\
\text { Value }=0 \text { for entering competition } \\
\text { (chooses WTA tournament) }\end{array}$ & Binary & 0.50 \\
\hline $\begin{array}{l}\text { Number of correct } \\
\text { sums in round } 1, \text { Task } 1 \\
\text { (SCOR1) }\end{array}$ & $\begin{array}{l}\text { Number of additions correctly solved } \\
\text { in round } 1 . \text { Controls for subject's } \\
\text { ability. }\end{array}$ & $\begin{array}{l}\text { Fuzzy set } \\
\text { calibration }\end{array}$ & 5.57 \\
\hline $\begin{array}{l}\text { Overconfidence } \\
\text { (OVERCONF) }\end{array}$ & $\begin{array}{l}\text { Value }=1 \text { for those overestimating } \\
\text { their position within the group in } \\
\text { round } 2 \\
\text { Value }=0 \text { otherwise }\end{array}$ & Binary & 0.24 \\
\hline $\begin{array}{l}\text { Risk aversion } \\
\text { (AVERISK) }\end{array}$ & $\begin{array}{l}\text { Value }=1 \text { for risk-averse subjects } \\
\text { Value }=0 \text { otherwise }\end{array}$ & Binary & 0.75 \\
\hline $\begin{array}{l}\text { Experience in } \\
\text { competitive sports } \\
\text { (SPOR) }\end{array}$ & $\begin{array}{l}\text { Value }=1 \text { for subjects with strong } \\
\text { experience in competitive sports } \\
\text { Value }=0 \text { otherwise }\end{array}$ & Binary & 0.81 \\
\hline $\begin{array}{l}\text { Experience in } \\
\text { videogames } \\
\text { (GAME) }\end{array}$ & $\begin{array}{l}\text { Value }=1 \text { for subjects with strong } \\
\text { experience in videogames } \\
\text { Value }=0 \text { otherwise }\end{array}$ & Binary & 0.59 \\
\hline $\begin{array}{l}\text { Cooperative personality } \\
(\mathrm{COOP})\end{array}$ & $\begin{array}{l}\text { Value }=1 \text { for cooperative subjects } \\
\text { Value }=0 \text { otherwise }\end{array}$ & Binary & 0.37 \\
\hline
\end{tabular}

68 subjects ( 31 men and 37 women). Decision in round 3 acts for the outcome of the FsQCA. 
Table 2. Analysis of necessary conditions

Outcome: dec

\begin{tabular}{lcc}
\hline Condition & Consistency & Coverage \\
\hline scor1 & 0.87 & 0.54 \\
SPOR & 0.82 & 0.51 \\
AVERISK & 0.71 & 0.47 \\
coop & 0.62 & 0.49 \\
overconf & 0.59 & 0.45 \\
GAME & 0.53 & 0.45 \\
GEN & 0.50 & 0.55 \\
gen & 0.50 & 0.46 \\
game & 0.47 & 0.57 \\
OVERCONF & 0.41 & 0.58 \\
COOP & 0.38 & 0.52 \\
averisk & 0.13 & 0.59 \\
spor & 0.29 & 0.46 \\
SCOR1 & 0.18 & 0.34 \\
GEN+SPOR & 0.52 & \\
OVERCONF+SPOR & & 0.51 \\
\hline Causal conditions with capital letter: indicate the presence of causal condition studied. & & \\
Causal conditions with small letter: indicate the absence of that condition. & \\
\hline
\end{tabular}


Table 3. Sufficient combinations of conditions for entering in a WTA tournament

Model 1. Outcome: dec

\begin{tabular}{lccc}
\hline Intermediate Solution & Raw & Unique & Consistency \\
& Coverage & Coverage & \\
\hline GAME*SPOR*averisk*coop & 0.15 & 0.15 & 0.83 \\
GEN*AVERISK*overconf*COOP & 0.15 & 0.12 & 1.00 \\
game*SPOR*OVERCONF*COOP & 0.09 & 0.09 & 1.00 \\
gen*game*SPOR*AVERISK & 0.09 & 0.09 & 0.75 \\
GEN*GAME*SPOR*COOP & 0.09 & 0.06 & 1.00 \\
GEN*game*spor*AVERISK*OVERCONF*coop & 0.06 & 0.06 & 1.00 \\
GEN*GAME*averisk*OVERCONF*coop & 0.03 & 0.03 & 1.00
\end{tabular}

Solution Coverage: 0.62

Solution Consistency: 0.91

Model 2. Outcome: dec (without gender as causal condition)

\begin{tabular}{lccc}
\hline Intermediate Solution & Raw & Unique & Consistency \\
& Coverage & Coverage & \\
\hline game*SPOR*AVERISK & 0.27 & 0.07 & 0.75 \\
GAME*SPOR*averisk*coop & 0.15 & 0.06 & 0.83 \\
game*AVERISK*OVERCONF* coop & 0.12 & 0.06 & 0.80 \\
GAME*averisk*OVERCONF*coop & 0.12 & 0.03 & 1.00 \\
game*AVERISK*overconf*COOP & 0.12 & 0.03 & 0.80 \\
game*SPOR*OVERCONF*scor1*COOP & 0.08 & 0.03 & 1.00 \\
Solution Coverage: 0.56 & & & \\
Solution Consistency: 0.83 & & & \\
\hline
\end{tabular}

Causal conditions with capital letter indicate the presence of causal condition studied.

Causal conditions with small letter indicate the absence of that condition.

*: Presence of both conditions. 
Figure 1. Correct sums per round in Task 1

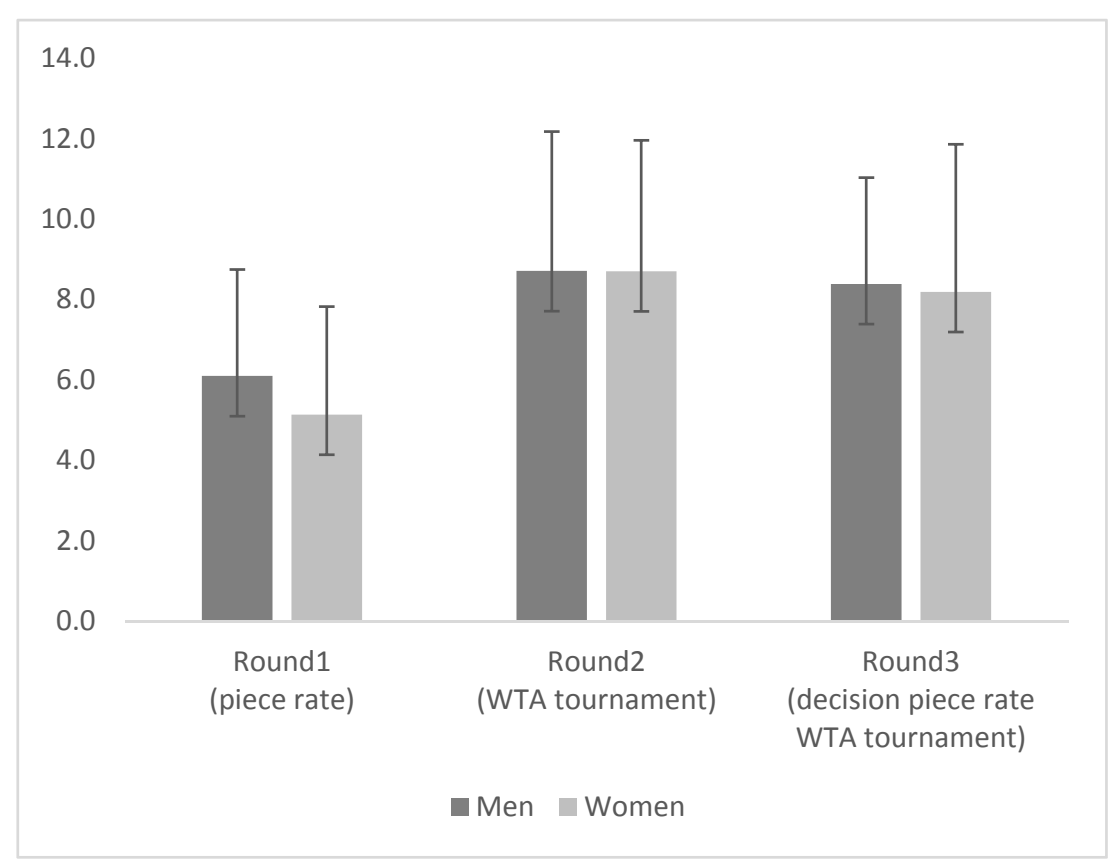

Means and standard deviations of correct sums by 68 subjects ( 31 men and 37 women) by round. 
Figure 2. Disaggregated results for Round 3 in Task 1

\section{A: Correct sums per payment scheme $\quad$ B: Frequency of WTA tournament's choice}

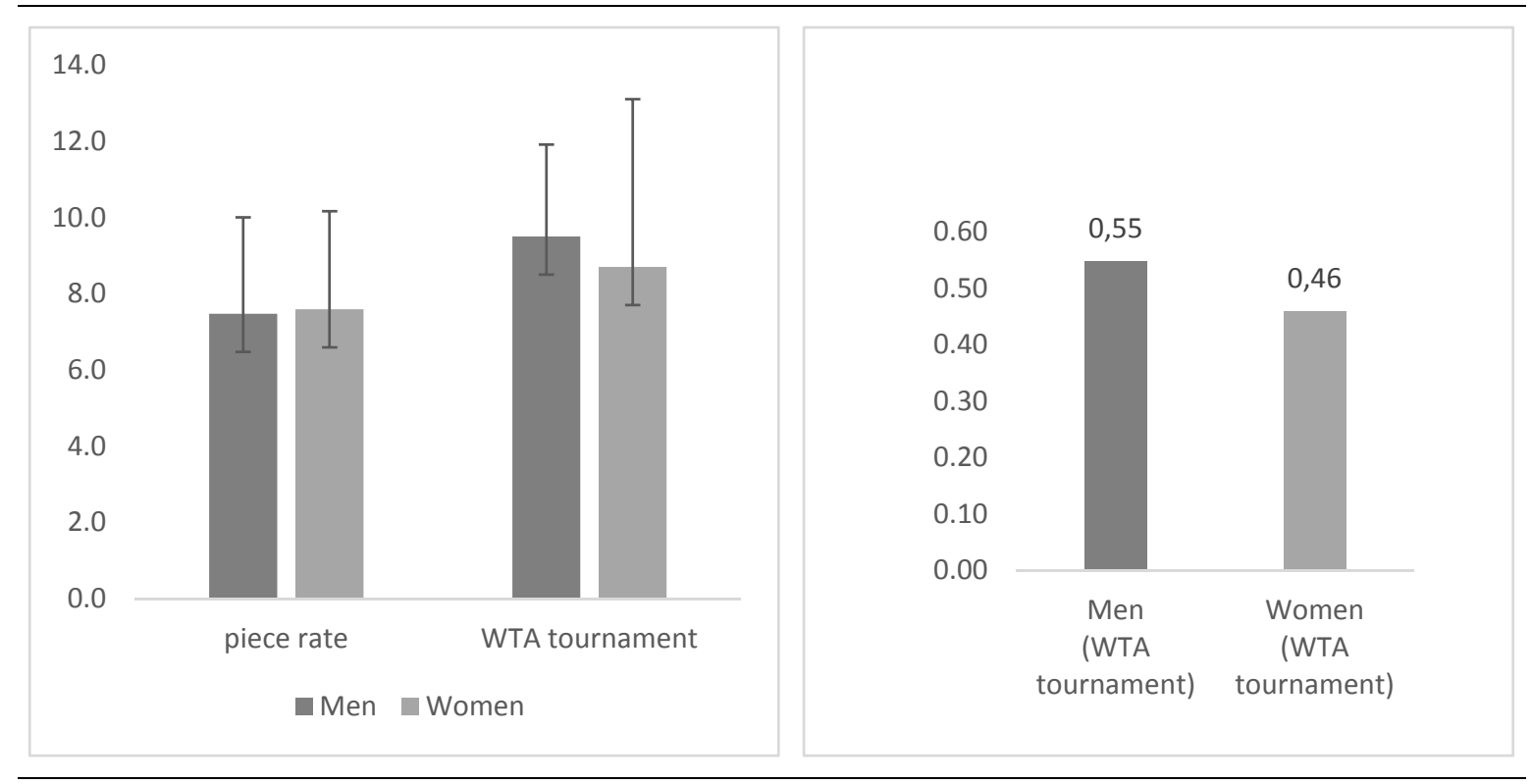

The total sample in round 3 consists of 68 subjects ( 31 men and 37 women).

14 men (45\%) and 20 women (54\%) choose not to compete (piece rate payjment).

17 men $(55 \%)$ and 17 women (46\%) choose to compete (WTA tournament payment). 